Çukurova Üniversitesi Mühendislik Mimarlık Fakültesi Dergisi, 33(4), ss. 89-96, Aralık 2018

Çukurova University Journal of the Faculty of Engineering and Architecture, 33(4), pp. 89-96, December 2018

\title{
Endüstriyel Atıksularda Mikroalgal Nütrient Giderimi ve Biyodizel Üretim Verimliliği: Süt Endüstrisi Örneği
}

\author{
Sevgi YILMAZ1 ${ }^{1}$ Fuat BUDAK ${ }^{* 1}$ \\ ${ }^{1}$ Çukurova Üniversitesi, Mühendislik Fakültesi, Çevre Mühendisliği Bölümü, Adana
}

$\ddot{\mathbf{O} z}$

Geliş tarihi: 26.08.2018 Kabul tarihi: 25.12.2018

\begin{abstract}
Son yıllarda mikroalgal arıtım teknolojileri endüstriyel ve tarımsal kökenli atıksuların artımında klasik atıksu arıtma sistemlerine karşı sürdürülebilir bir alternatif olarak görülürken, elde edilen mikroalgal biyokütle de yenilenebilir bir enerji kaynağı olarak oldukça önem kazanmaktadır. Bu çalışmada süt endüstrisi atıksularında üretilen Chlorella vulgaris'in nütrient giderim ve biyokütle üretim verimi potansiyelinin araştırılması amaçlanmıştır. Çalışmada kullanılan atıksu, Adana' da süt endüstrisi sektöründe faaliyet gösteren bir firmadan sağlanmıştır. Araştırma sonuçları, on günlük üretim sürecinde, Chlorella vulgaris' in toplam azot (TA) ve toplam fosfor (TF) giderim verimlerinin sirasiyla $\% 95,3$ ve $\% 92,7$ olduğu, $0.074 \mathrm{~g} \mathrm{~L}^{-1}$ gün$^{-1}$ olan maksimum kuru madde miktarının ise deneysel çalışmanın ikinci gününde elde edildiğini göstermiştir. Çalışmadan elde edilen veriler Chlorella vulgaris'in süt endüstrisi atıksularında etkin bir nütrient giderimi sağladığını ve süt endüstrisi atıksularının sürdürülebilir mikroalgal biyokütle ve biyodizel üretiminde önemli bir potansiyele sahip olduğunu göstermiş̧ir.
\end{abstract}

Anahtar Kelimeler: Mikroalg, Süt endüstrisi atıksuyu, Nütrient giderimi, Biyoyakıt

\section{Microalgal Nutrient Removal and Biodiesel Production Potential in Industrial Wastewater: The Case of Dairy Industry}

\begin{abstract}
The use of microalgal wastewater treatment technologies for agri-industrial wastewater has shown to be a sustainable alternative to conventional treatment systems. Furthermore, the biomass obtained from microalgae also has been recently considered as a renewable source of biofuel. The aim of this study is to investigate the nutrient removal and biomass production efficiency of Chlorella vulgaris cultivated in dairy wastewater. Wastewater used in this research was taken from a dairy industry facility located in Adana. The results showed that by the end of a 10-day batch culture, Chlorella vulgaris could remove total nitrogen (TN) and total phosphorus (TP) by $95.3 \%$ and $92.7 \%$ respectively and maximum biomass productivity of $0,074 \mathrm{~g}$ dry-weight/L/day was achieved to at second day of growth. The results of the study indicated that Chlorella vulgaris effectively removed nutrients from dairy effluent. Dairy wastewater has great potential to cultivate microalgae for biomass and biodiesel production in a sustainable manner.
\end{abstract}

Keywords: Microalgae, Dairy wastewater, Nutrient removal, Biofuels

*Sorumlu yazar (Corresponding author): Fuat BUDAK, fbudak@cu.edu.tr 


\section{GíRiș}

Hızlı nüfus artışı ile birlikte gelişen endüstriyel ve tarımsal modernizasyon, alıcı ortama verilmeden önce mutlaka arıtılması gereken yüksek oranda evsel, endüstriyel ve tarımsal atıksuların oluşumuna neden olmaktadır. Söz konusu atıksular su kaynaklarının kalitatif ve kantitatif sürdürülebilirliği üzerinde çok ciddi tehditler oluşturmaktadır. Uygun arıtma sistemleri kullanılarak aritılmadan alıcı ortama verilen atıksularda yüksek miktarda bulunan azot ve fosfor elementleri ötrofikasyona neden olarak ekosisteme zarar vermektedir. Alıcı ortama verilen bu sular, düşük çözünmüş oksijen konsantrasyonu, istenmeyen $\mathrm{pH}$ değişimleri ve toksik etkileriyle çevre kirliliğine yol açmaktadır. Atıksularda bulunan ve kirliliğe yol açan bu nütrientleri (azot, fosfor) atıksudan uzaklaştırmak için çeşitli arıtım teknolojileri geliştirilmiştir. Ancak, bu proseslerin önemli bir bölümü yüksek yatırım ve işletme maliyeti, karmaşık işletim prosedürü, önemli miktarda enerji, kimyasal madde kullanımı ve büyük miktarlarda atık çamur oluşumu gibi sorunları da beraberinde getirmektedir. Bu nedenle atıksuların ileri arıtımı için gerekli olan enerji ve yüksek finansman ihtiyacı, düşük maliyetli, sürdürülebilir ve çevreci arıtım sistemleri yaklaşımlarının geliştirilmesini teşvik etmiştir [1].

Günümüz koşullarında dünya, olumsuz etkileri giderek artış gösteren küresel 1sınma, enerji ve besin yetersizliği gibi önemli pek çok zorlukla karşı karşıyadır. Son yıllarda artan küresel enerji ihtiyacinın \%80'ini fosil yakitlardan karşılanmaktadır. Bu enerji formunun yenilenemez bir kaynak oluşu ile birlikte enerji krizi 21. yüzyılda insanoğlunun karşılaştığı en önemli güçlüklerden birisidir. Her ne kadar diğer enerji kaynakları ile karşılaştırıldığında düşük maliyetli olması fosil yakıtları cazip bir enerji kaynağı haline getirse de özellikle atmosfere yaydığ emisyonlarının küresel iklim değişikliğine olan olumsuz etkileri nedeniyle uzun dönemde enerji üretiminde fosil yakıt kullanımı sürdürülebilir bir durum değildir. Dolayısıyla yakın gelecekte fosil yakıtlar yerini yenilenebilir, çevre dostu enerji kaynaklarına bırakmak durumundadır.

En önemli yenilenebilir enerji kaynaklarından birisi de biyoyakıtlardır. İlk nesil biyoyakıtların şeker kamışı, kanola, mısır gibi tarımsal kaynaklı ürünlerden elde edilmiştir. Ancak tarımsal kaynaklı biyoyakıtların ekonomik olarak fosil yakıtlar ile rekabet edememesi ve özellikle verimli arazilerin kullanılması sonucu gıda güvencesini tehlikeye atması gibi önemli dezavantajları bulunmaktadır. Bitkisel kökenli lignoselülozik biyokütleden elde edilen ikinci nesil biyoyakıt üretiminde ise gıda biyoyakıt rekabeti sorunu yaşanmamasına rağmen lignoselülozik biyokütleden lignini ayırma işleminin yüksek maliyetli oluşu önemli bir sorun oluşturmuştur [2-4]

Son yıllarda biyoyakıt üretiminde yoğun araştırmalara konu olan mikroalgler, yüksek fotosentetik verimleri, tarıma elverişli olmayan arazilerde üreyebilmesi, atıksuların değerlendirilerek aynı zamanda atıksu arıtma işlemini gerçekleştirilmesi, iklim değişikliğine neden olan baca gazlarından $\mathrm{CO}_{2}$ 'i asimile ederek kullanması ve biyoyakıt dışında değerli yan ürünler sunması nedeniyle biyoyakıt üretiminde kullanılacak yağlı bitkilere göre çok daha önemli avantajlara sahiptir. Biyokütle ve biyodizel verimliliği açısından mikroalgler yağlı tohumlara göre önemli bir üstünlüğe sahiptir. Yağlı tohumların biyokütle verimi 3-13 ton/ha arasında değişirken bu değer mikroalgler de 50-150 ton/ha arasındadır. Yağ verimi açısından bakıldığında, örneğin kanoladan hektar başına 1,5 ton yağ elde edilirken bu oran mikroalgler için 40 ton/ha'a kadar çıkmaktadır [2].

Mikroalgler $\mathrm{CO}_{2}$ 'i genel olarak; atmosferde mevcut bulunan $\mathrm{CO}_{2}$, enerji santralleri ve endüstriyel işletmelerin neden olduğu $\mathrm{CO}_{2}$ ve çözünebilir karbonattan $\mathrm{CO}_{2}$ 'i büyümeleri için gerekli olan karbon kaynağı olarak kullanabilirler. Mikroalgler fotosentez sürecinde bünyesine aldıkları $\mathrm{CO}_{2}{ }^{\prime} \mathrm{i}$ karbonhidrat, lipit ve protein formuna dönüştürür. Böylelikle atmosferden $\mathrm{CO}_{2}$ gazını yakalayarak küresel ısınmanın etkilerini azaltabilirler [2-5]. 
Çalışmada yeşil mikroalgler grubuna ait olan Chlorella vulgaris'in süt endüstrisi atıksularında nütrient giderimi, mikroalgal biyokütle üretimi ve yağ verimi potansiyelinin araştırılması amaçlanmıştır.

\section{2. ÖNCEKİ ÇALIŞMALAR}

Li ve arkadaşları [6] Chlorella sp. ile kentsel atıksularda nütrient giderimi, biyokütle ve biyodizel üretim verimini araştırdıkları 14 günlük deneme süreli çalışmalarında $\mathrm{NH}_{4}^{+}$, TA, TF ve KOİ giderim verimleri sirasiyla $\% 93,9,89,1,80,9$ ve 90,8 olarak bulmuşlardır. Çalışmada Chlorella sp.'nin biyokütle verimi $0,92 \mathrm{~g} / \mathrm{L}$ gün, biyodizel verimi ise $0,12 \mathrm{~g} / \mathrm{L}$ gün olarak tespit edilmiştir.

Lu ve Arkadaşları [7] Chlorella sp. için besi yeri olarak bir et işleme tesisinin atıksuları seçtikleri çalışmalarında, besin profilini dengelemek ve düşük maliyetle biyokütle verimini artırmak için atıksuların karışımına dayanan yenilikçi bir mikroalg yetiştirme modeli geliştirmiş̧lerdir. Çalışmada karışık atıksuların mikroalg gelişimi üzerinde biyokütle veriminin $(0,675-1,538 \mathrm{~g} / \mathrm{L})$, tek tip atıksuda yetiştirilen mikroalg veriminden çok daha yüksek olduğunu raporlamışlardır. Çalışmada yeterli azota sahip karışık atıksularda, giderim veriminin $\mathrm{NH}_{4}{ }^{+}$için \%68,75-90,38 olduğu ve TA giderim veriminin \%30,06-50,94 oranında iyileştirildiği bildirilmiştir.

Choi [8], yaptığ çalışmada, Chlorella vulgaris ile süt endüstrisi atıksularının arıtılmasını araştırmış ve 10 gün süren denemenin sonunda giderim verimlerini; BOİ \%85,61, KOİ \%80,62, AKM $\% 29,10$, TA $\% 85,47$ ve TF $\% 65,96$ olarak bulmuştur. Çalışmada elde edilen verilerin ışığında süt endüstrisi atıksularının mikroalglerle arıtılmasının çevre dostu pratik bir strateji olduğu rapor edilmiştir.

\section{MATERYAL VE METOT}

\subsection{Materyal}

Çalışmada yeşil mikroalg türü olan Chlorella vulgaris kullanılmıştır. Deneysel çalışmada kullanılan atıksu, Adana'da süt endüstrisi sektöründe faaliyet gösteren bir firmanın arıtma tesisi çıkışından alınmıştır. Alınan atıksu bekletilmeden aynı gün analizleri yapılarak deneysel çalışmada kullanılmak üzere hazır hale getirilmiştir. Süt endüstrisi arıtma tesisi çıkış suyundan alınan atıksuyun karakterizasyonu Çizelge 1'de verilmiştir.

Çizelge 1. Süt endüstrisi arıtma tesisi çıkış atıksu karakterizasyonu

\begin{tabular}{|c|c|}
\hline Parametre & Konsantrasyon $(\mathbf{m g} / \mathbf{L})$ \\
\hline TA & 55,0 \\
\hline TF & 12,3 \\
\hline KOI & 48,0 \\
\hline $\mathrm{pH}$ & 7,6 \\
\hline
\end{tabular}

\subsection{Metot}

Stok kültürden alınarak \%1,5 agarlı besi yerine yayma tekniği ile ekilen ve inkübasyon sürecine bırakılan Chlorella vulgaris kültürü, Bold Basal Medium (BBM) sıvı besi ortamında, çalışmada aşı olarak kullanılmak üzere çoğaltılmıştır. Elde edilen Chlorella vulgaris başlangıç kültürleri 2 L'lik erlenlere alınarak deneme başlatılmış, daha sonra yüksek oranlı mikroalg havuzunda üretime devam ettirilmiştir. Deneysel çalışma boyunca sıcaklık $25{ }^{\circ} \mathrm{C}$ olarak ayarlanmış ve sabit tutulmuştur. Aydınlık/karanlık döngüsü 14/10 saat, aydınlanma

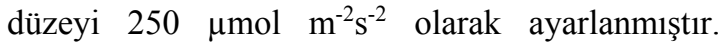
Havalandırma işlemi motorlu hava pompası ile yapılmıştır. Kültürlerin homojenizasyonu sağlamak için çalkalayıcılar kullanılmıştır.

Besi ortamı olarak kullanılan atıksu filtreden geçirilerek $121{ }^{\circ} C^{\prime}$ de 1,5 atm basınç altında 15 dakika süresince otoklavlanmıştır. Sterilizasyonu yapılan atıksu ile aşı olarak kullanılan Chlorella vulgaris 1:10 (v/v) oranında karıştırılmıştır. Çalışmada BBM ortamında ve aynı şartlarda üretilen Chlorella vulgaris kontrol grubu olarak kullanılmıştır. Deneysel çalışma 3 tekerrürlü yapılmış olup, sonuçlar ortalama değerler alınarak verilmiştir. Deneysel çalışma süresince yapılan tüm analizler aynı gün aynı saatte tekrarlanmıştır. Çalışmada TA, TF ve KOİ konsantrasyonları 
UV/VIS spektrofotometrede (Merck Spektroquant Prove 100) Merck Spectroquant test kitleri ile belirlenmiştir. Deneysel çalışma süresince Chlorella vulgaris yoğunluğu günlük olarak spektrofotometre ile $680 \mathrm{~nm}$ dalga boyunda ölçülmüştür [9]. Mikoalgal biyokütlenin hasadı 5000 rpm'de 10 dakika süreli santrifüjleme ile yapılmıştır. Elde edilen mikroalg çamuru cam petriler içinde etüvde kurutulmuştur. Elde edilen kuru mikroalgal kütle yağ analizi için hazır hale getirilmiştir. Deneysel çalışma Çukurova Üniversitesi Çevre Mühendisliği Bölümü FitoBiyoremediasyon Laboratuvarında bulunan tam kontrollü mikroalg büyüme odasında gerçekleştirilmiştir.

\section{ARAŞTIRMA BULGULARI}

\subsection{Mikroalgal Büyüme ve Biyokütle Verimi}

Araştırmada mikroalgal büyüme klorofil absorpsiyonun en yüksek olduğu $680 \mathrm{~nm}$ dalga boyunda ölçülen optik yoğunluk değerleriyle izlenmiştir. Günlük olarak ölçülen optik yoğunluk değerleri deneysel çalışma süresince mikroalgal büyümenin göstergesi olarak değerlendirilmiştir. 10 günlük deneysel çalışmanın 0-4 günleri arasındaki dönem, mikroalgal büyümenin en hızlı olduğu dönem olmuştur. 4. günden sonra mikroalgal büyüme hızının giderek azaldığ 1 , 9. günden sonra duraklama dönemine girildiği gözlenmiştir (Şekil 1.)

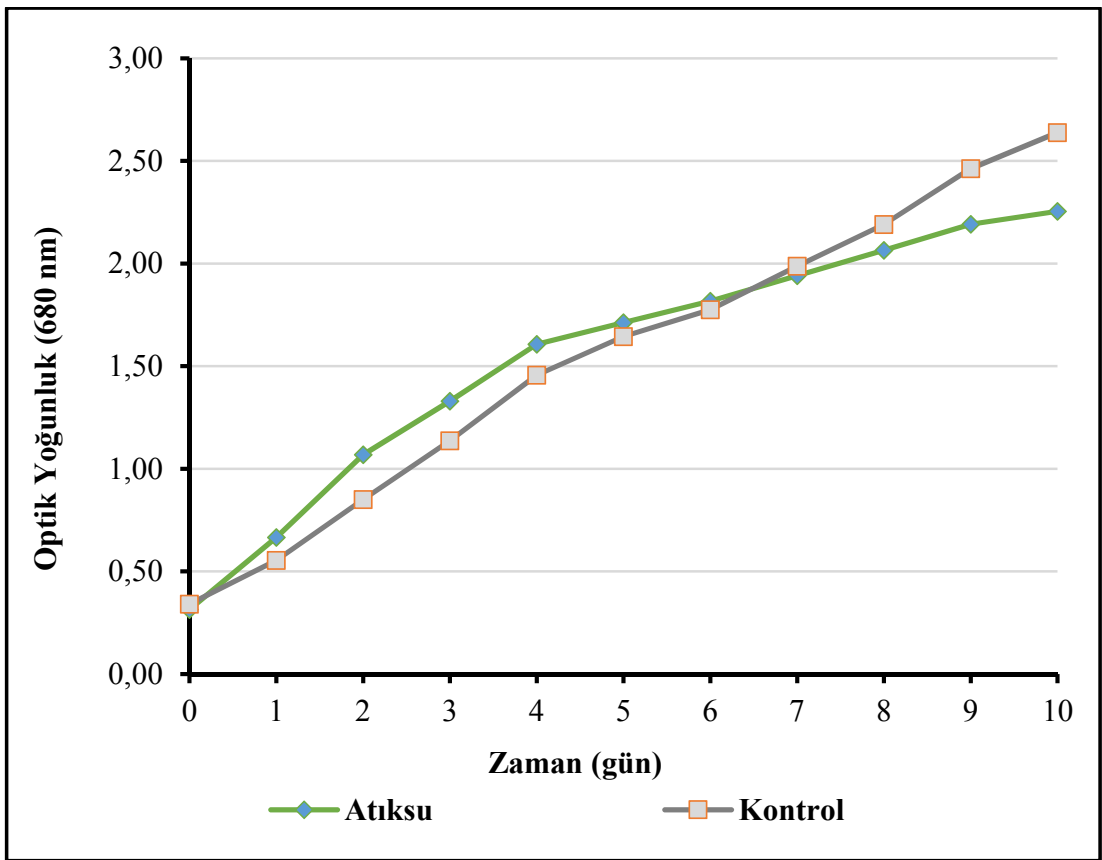

Şekil 1. Mikroalgal büyüme ve deneme süresince değişimi

Elde edilen büyüme eğrisi BBM ortamında aynı koşullarda üretilen ve Kontrol olarak kullanılan seri ile karşılaştırıldığında, deneysel çalışmanın 6. gününe kadar hemen hemen benzer bir büyüme eğilimi gösterdiği gözlenmiştir (Şekil 1). Dolayısıyla büyüme eğrisi dikkate alındığında süt endüstrisi atıksularında bulunan nütrientlerin, deneysel çalışmada kullanılan mikroalg türü
Chlorella vulgaris tarafindan kullanılarak değerlendirildiği ve normal bir gelişim göstererek çoğaldığı anlaşılmaktadır. Araştırmada kuru biyokütle günlük olarak ölçülen optik yoğunluk değerleri ile kuru madde miktarları arasında oluşturulan ve aşağıda verilen regresyon Eşitlik 1 ile hesaplanmıştır. 
Kuru ağırlık $\left(\mathrm{mg} \mathrm{L}^{-1}\right)=183,68 * \mathrm{OD}_{680}+0,83$ $\mathrm{R}^{2}=0,9984$

Eşitlik 1'de $\mathrm{OD}_{680}$ günlük olarak izlenen optik yoğunluk değerlerini göstermektedir. 10 günlük deneysel çalışma süresince kuru ağırlık olarak elde edilen toplam mikroalgal biyokütle verimi $0,414 \mathrm{~g}$ $\mathrm{L}^{-1}$ ve $0,036 \mathrm{~g} \mathrm{~L}^{-1}$ gün $^{-1}$ olmuştur. Maksimum kuru madde miktarı $0,074 \mathrm{~g} \mathrm{~L}^{-1}$ gün $^{-1}$ ile deneysel çalışmanın 2. gününde elde edilmiştir. Mikroalgal büyümenin en hızlı olduğu faz olan ilk 4 günlük dönemde elde edilen kuru madde miktarı ise $0,059 \mathrm{~g} \mathrm{~L}^{-1}$ gün${ }^{-1}$ olarak gerçekleşmiştir.

Deneysel çalışma süresince mikroalglerin günlük spesifik büyüme oranları Eşitlik 2 kullanılarak hesaplanmıştır.

$\mu=\frac{\ln X_{t_{2}}-\ln X_{t_{1}}}{t_{2}-t_{1}}$

Eşitlik 2'de, $\mu$ spesifik büyüme oranını, $X_{t_{2}}$ ve $X_{t_{1}}$ sırasıyla $t_{2}$ ve $t_{1}$ zamanlarındaki (gün) biyokütle konsantrasyonun ifade etmektedir. Deneysel çalışmanın sürdüğü 10 günlük dönemde ortalama günlük büyüme oranı 0,086 olarak bulunmuştur. Günlük maksimum büyüme oranı $(0,326)$ araştırmanın ilk gününde elde edilmiştir. Denemenin ilk 4 gününde ortalama günlük spesifik büyüme oranı 0,177 olarak gerçekleşmiş olup, söz konusu ilk 4 günlük dönem biyokütle verimliliğinin en yüksek olduğu üretim dönemi olmuştur. Çalışmada Chlorella vulgaris'in yağ verimliliği $\% 20,6$ olarak bulunmuştur. Mikroalgal yağların biyodizele dönüşüm veremliliği ise seçilen yöntem ve kullanılan çözücülere göre değişim göstermekte olup, Chlorella sp. türlerinden elde edilen mikroalgal yağların biyodizele dönüşümünde optimize edilmiş klasik transesterfikasyon yöntemlerinde \%80'e, reaksiyonlara enzim (lipaz) katalizörlerin eklenmesi ile ise \%97-99'a varan bir verimlilik elde edilebilmektedir [10,11].

\subsection{Nürtient Giderimi}

Çalışma kapsamında süt endüstrisinden alınan ve denemede besi ortamı olarak kullanılan arıtma tesisi çıkış atıksuyu başlangıç TA konsantrasyonu $55 \mathrm{mg} / \mathrm{L}$ olarak belirlenmiştir.

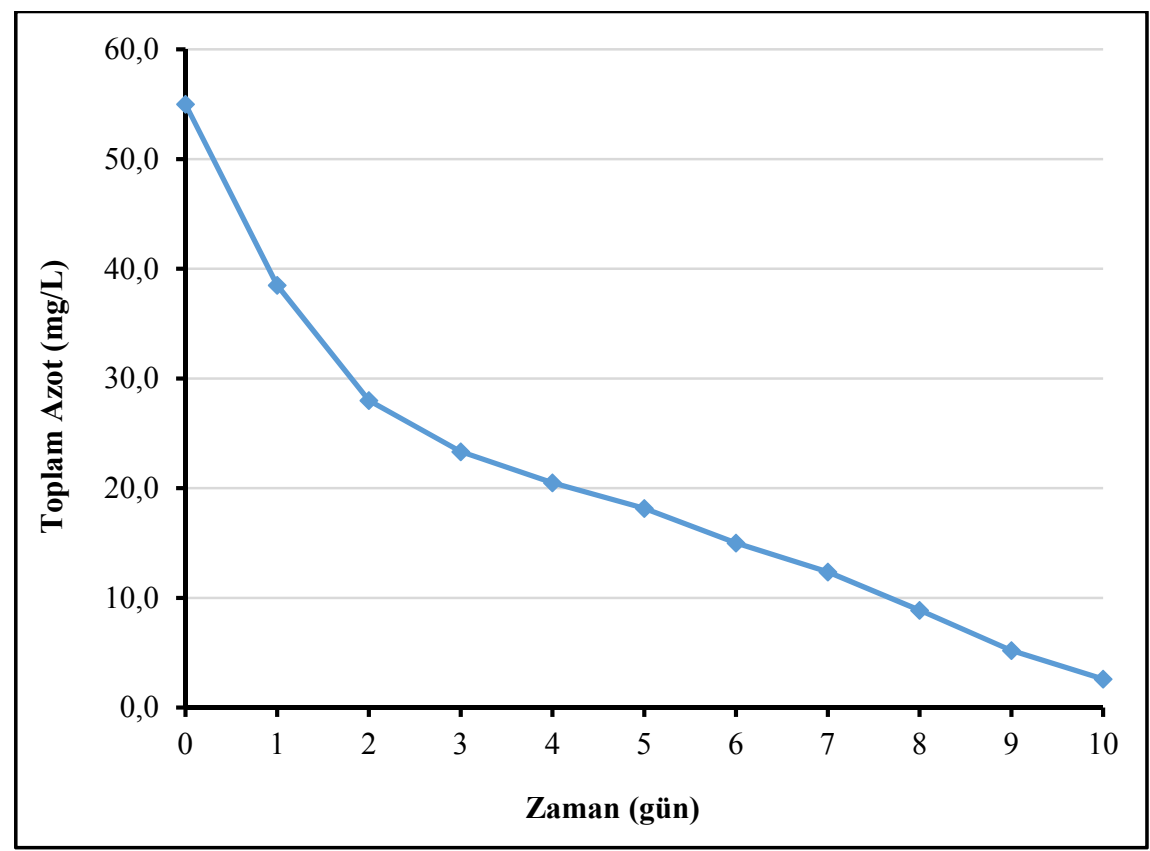

Şekil 2. Deneme süresince TA konsantrasyonun günlük değişimi (mg/L) 
Deneme süresince TA konsantrasyonundaki değişim günlük ölçüm yapılarak izlenmiştir. 10 günlük deneysel çalışma süresince Chlorella vulgaris, süt endüstrisi atıksuyunda bulunan azot içeriğinden etkili bir şekilde faydalandı̆̆ gözlenmiştir. Deneysel çalışmanın sona erdiği 10. günün sonunda Chlorella vulgaris' in atıksudaki TA konsantrasyonunu 55,00 mg/L'den 2,60 mg/L'ye düşürdüğü tespit edilmiştir. Mikroalgal büyümenin en hızlı olduğu ilk 4 günün sonuda TA konsantrasyonu hizlı azalarak 20,50 mg/L düşmüştür. Çalışmada elde edilen azot giderim verimi 2,60-16,50 $\mathrm{mg} \mathrm{L}^{-1}$ gün $^{-1}$ arasında değişmiş olup, ortalama $2,54 \mathrm{mg} \quad \mathrm{L}^{-1}$ gün $^{-1}$ olarak gerçekleşmiştir. TA konsantrasyonunun zamana göre değişimi Şekil 2'de verilmiştir. Deneysel çalışma süresince yapılan ölçümlerden elde edilen bulgular Chlorella vulgaris'in süt endüstrisi arıtma tesisi çıkış atıksuyunda \%95,27 oranında TA giderimi sağladığını göstermiştir. $\mathrm{Bu}$ oran denemenin ilk 4 günü sonunda ise $\% 62,73$ olarak gerçekleşmiştir.

Çalışmada besi ortamı olarak kullanılan atıksuyun başlangıç TF konsantrasyonu $12,30 \mathrm{mg} / \mathrm{L}$ olarak belirlenmiştir. Deneysel çalışma süresince yapılan ölçümler 10. günün sonunda TF konsantrasyonunun $0,90 \mathrm{mg} / \mathrm{L}$ 'ye kadar düştüğünü göstermiştir. TF konsantrasyonun zamana göre günlük değişimi Şekil 3'te verilmiştir.

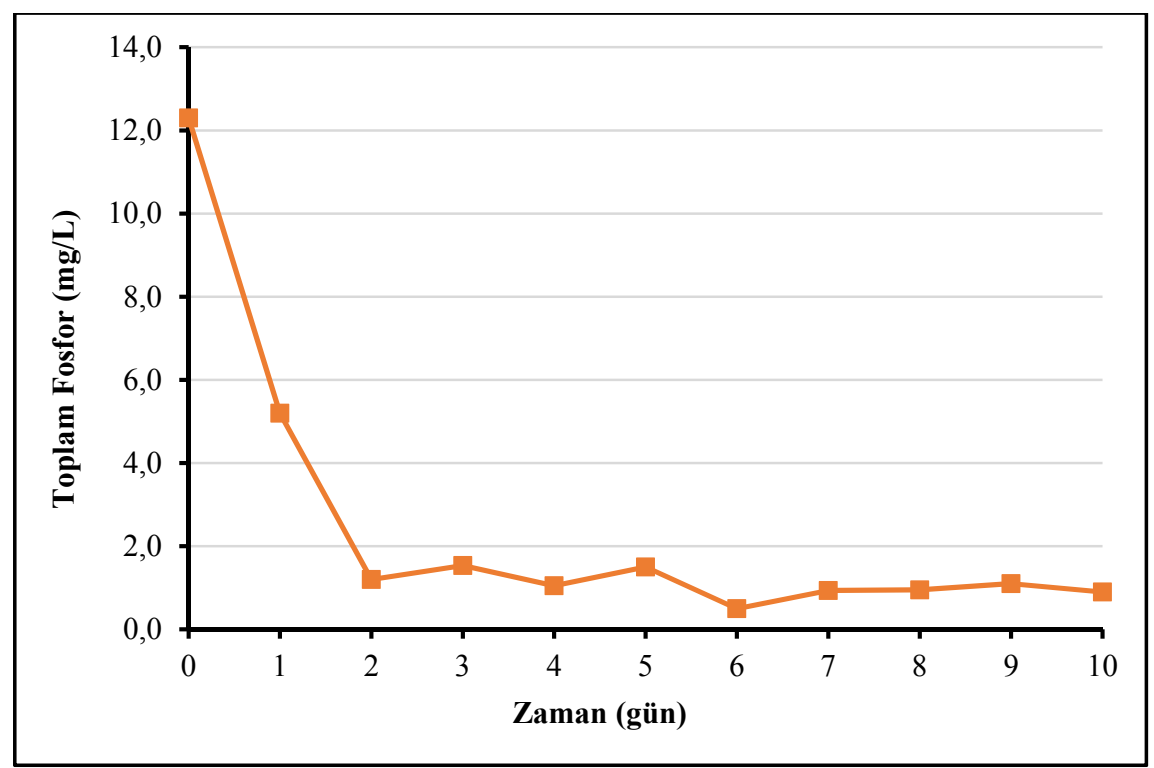

Şekil 3. Deneme Süresince TF Miktarının Günlük Değişimi (mg/L)

TF denemenin ilk 2 gününde büyük oranda giderilmiştir. TF giderim verimi ilk 2 gün sonunda \%90,24 olurken, deneysel çalışmanın sonucunda ulaşılan verim ise \%92,68 olmuştur. Çalışmada elde edilen TF giderim verimi ilk 2 günlük dönemde $5,50 \mathrm{mg} \mathrm{L}^{-1}$ gün $^{-1}$ iken, 10 günlük deneysel çalışma süresince ortalama $1,14 \mathrm{mg} \mathrm{\textrm {L } ^ { - 1 }}$ gün $^{-1}$ olarak gerçekleşmiştir.

Araştırmadan elde edilen nütrient giderim verimleri diğer çalıșmalardan elde edilen verilerle karşılaştırıldığında özellikle süt endüstrisi atıksularında yapılan çalışmalara göre daha yüksek olduğu diğer atık sularda yapılan çalışmalarla ise yaklaşık olarak benzer sonuçların elde edildiği görülmüştür [2,12-14].

\section{SONUÇLAR}

Çalışma sonunda Chlorella vulgaris süt endüstrisi atıksularında biyokütle artışı gösterirken aynı zamanda etkin bir nütrient giderimi sağlamıştır. On günlük deneme süresince kuru ağırlık olarak elde edilen mikroalgal biyokütle verimi $0,036 \mathrm{~g} \mathrm{~L}^{-1}$ gün$^{-1}$ 
olmuştur. Maksimum kuru madde miktarı $0,074 \mathrm{~g} \mathrm{~L}^{-1}$ gün $^{-1}$ ile denemenin ikinci gününde elde edilmiștir. TA giderim verimi \%95,27 TF giderimi ise $\% 92,68$ olarak bulunmuştur. Çalışmadan elde edilen veriler süt endüstrisi atıksularında mikroalglerin (Chlorella vulgaris) verimli bir şekilde çoğalma ve biyokütle üretimi sürecinde, atıksuda bulunan nürientleri asimile edilerek ileri atıksu arıtımı gerçekleştirme ve elde edilen mikroalgal biyokütlenin biyoyakıt olarak kullanılma potansiyelinin olduğunu göstermiştir.

\section{TEȘEKKÜR}

Bu çalışma, FYL-2016-6697 nolu proje kapsamında yapılmış olup Çukurova Üniversitesi Rektörlüğü BAP Koordinasyon Birimi tarafından desteklenmiştir.

\section{KAYNAKLAR}

1. Christenson, L., Sims, R., 2011. Production and Harvesting of Microalgae for Wastewater Treatment, Biofuels, and Bioproducts. Biotechnology Advances, 29(6), 686-702.

2. Kumar, K., Mishra, S.K., Shrivastav, A., Park, M.S., Yang, J.W., 2015. Recent Trends in the Mass Cultivation of Algae in Raceway Ponds. Renewable \& Sustainable Energy Reviews, 51, 875-885.

3. Pittman, J.K., Dean, A.P., Osundeko, O., 2011. The Potential of Sustainable Algal Biofuel Production Using Wastewater Resources. Bioresource Technology, 102(1), 17-25.

4. Wu, Y.H., Hu, H.Y., Yu, Y., Zhang, T.Y., Zhu, S.F., Zhuang, L.L., Zhu, S.F., Zhuang, L.L., Lu, Y., 2014. Microalgal Species for Sustainable Biomass/lipid Production Using Wastewater as Resource: A review. Renewable and Sustainable Energy Reviews, 33, 675-688.

5. Brennan, L., Owende, P., 2010. Biofuels from Microalgae: A Review of Technologies for Production, Processing, and Extractions of Biofuels and Co-Products. Renewable and Sustainable Energy Reviews, 14(2), 557-577.

6. Li, Y., Chen, Y.F., Chen, P., Min, M., Zhou, W., Martinez, B., Zou, J., Ruan, R., 2011. Characterization of a Microalga Chlorella Sp.
Well Adapted to Highly Concentrated Municipal Wastewater for Nutrient Removal and Biodiesel Production. Bioresource Technology, 102(8), 5138-5144.

7. Lu, Q., Zhou, W., Min, M., Ma, X., Chandra, C., Doan, Y.T., Ma, Y., Zheng, H., Cheng, S., Griffith, R, Chen, P., Chen, C., Urriola, P.E, Shurson, G.C., Gislerød, H.R., Ruan, R., 2015. Growing Chlorella sp. on Meat Processing Wastewater for Nutrient Removal and Biomass Production. Bioresource Technology, 198, 189-197.

8. Choi, H.J., Lee, S.M., 2012. Effects of Microalgae on the Removal of Nutrients from Wastewater: Various Concentrations of Chlorella vulgaris. Environ Eng Res, 17(17), 3-8.

9. Wang, L., Min, M., Li, Y., Chen, P., Chen, Y., Liu, Y., Wang, Y., Ruan, R., 2010. Cultivation of Green Algae Chlorella sp. in Different Wastewaters from Municipal Wastewater Treatment Plant. Applied Biochemistry and Biotechnology, 162(4), 1174-1186.

10. Wang, Y., Liu, J., Gerken, H., Zhang, C., Hu, Q., Li, Y., 2014. Highly-Efficient Enzymatic Conversion of Crude Algal Oils into Biodiesel. Bioresour Technol, 172 (2014), 143-149.

11. Wu, S.L., Song, L., Sommerfeld, M., Hu, Q., Chen, W., 2017. Optimization of an Effective Method for the Conversion of Crude Algal Lipids into Biodiesel. Fuel, 197, 467-473.

12. Choi, H.J., Lee, S.M., 2012. Effects of Microalgae on the Removal of Nutrients from Wastewater: Various Concentrations of Chlorella Vulgaris. Environ Eng Res, 17(17), 3-8.

13. Li, C., Yang, H., Li, Y., Cheng, L., Zhang, M., Zhang, L., Wang, W., 2013. Novel Bioconversions of Municipal Effluent and $\mathrm{CO}_{2}$ into Protein Riched Chlorella Vulgaris Biomass. Bioresource Technology, 132, 171-177.

14. Sreekanth, D., Pooja, K., Seeta, Y., Himabindu, V., Reddy, P.M., 2014. Bioremediation of Dairy Wastewater Using Microalgae for the Production of Biodiesel. IJSEAT, 2(11), 783-791. 
